\title{
Adjuvant therapy of melanoma with interferon: lessons of the past decade
} Paolo A Ascierto ${ }^{1}$ and John M Kirkwood*2,3

\author{
Address: ${ }^{1}$ Unit of Medical Oncology and Innovative Therapy, Melanoma Cooperative Group, National Tumor Institute, Naples, Italy, ${ }^{2}$ Department \\ of Medicine, Division of Hematology/Oncology, University of Pittsburgh, USA and ${ }^{3}$ Melanoma and Skin Cancer Program, University of Pittsburgh \\ Cancer Institute, USA \\ Email: Paolo A Ascierto - pasciert@tin.it; John M Kirkwood* - KirkwoodJM@upmc.edu \\ * Corresponding author
}

Published: 27 October 2008

Journal of Translational Medicine 2008, 6:62 doi:10.1 I86/1479-5876-6-62
Received: 21 August 2008

Accepted: 27 October 2008

This article is available from: http://www.translational-medicine.com/content/6/I/62

(c) 2008 Ascierto and Kirkwood; licensee BioMed Central Ltd.

This is an Open Access article distributed under the terms of the Creative Commons Attribution License (http://creativecommons.org/licenses/by/2.0), which permits unrestricted use, distribution, and reproduction in any medium, provided the original work is properly cited.

\begin{abstract}
The effect of interferon alpha (IFN $\alpha 2$ ) given alone or in combination has been widely explored in clinical trials over the past 30 years. Despite the number of adjuvant studies that have been conducted, controversy remains in the oncology community regarding the role of this treatment.

Recently an individual patient data (IPD) meta-analysis at longer follow-up was reported, showing a statistically significant benefit for IFN in relation to relapse-free survival, without any difference according to dosage $(p=0.2)$ or duration of IFN therapy $(p=0.5)$. Most interestingly, there was a statistically significant benefit of IFN upon overall survival (OS) that translates into an absolute benefit of at least $3 \%(\mathrm{Cl} \mathrm{I}-5 \%)$ at 5 years. Thus, both the individual trials and this meta-analysis provide evidence that adjuvant IFN $\alpha 2$ significantly reduces the risk of relapse and mortality of highrisk melanoma, albeit with a relatively small absolute improvement in survival in the overall population.

We have surveyed the international literature from the meta-analysis (2006) to summarize and assimilate current biological evidence that indicates a potent impact of this molecule upon the tumor microenvironment and STAT signaling, as well as the immunological polarization of the tumor tissue in vivo. In conclusion, we argue that there is a compelling rationale for new research upon IFN, especially in the adjuvant setting where the most pronounced effects of this agent have been discovered. These efforts have already shed light upon the immunological and proinflammatory predictors of therapeutic benefit from this agent - that may allow practitioners to determine which patients may benefit from IFN therapy, and approaches that may enable us to overcome resistance or enhance the efficacy of IFN. Future efforts may well build toward patientoriented therapy based upon the knowledge of the unique molecular features of this disease and the immune system of each melanoma patient.
\end{abstract}

\section{Introduction}

It has been more than 10 years since the pivotal trial E1684 first showed improvement in overall survival (OS) for melanoma patients treated with adjuvant high-dose interferon (HDI) [1], but controversies continue regarding the use of interferon (IFN) as adjuvant therapy in melanoma patients. In fact, despite numerous studies of adjuvant therapy, there is perhaps less consensus regard- 
ing the treatment of melanoma patients at high risk for relapse now than at any time since the FDA approval of this regimen in 1996. Parameters that may guide the consideration of adjuvant therapy, and when interferon (IFN) is considered whether it is shorter courses or lower dosages for longer intervals remain highly variable across the globe. In recent years, several reviews exploring these issues [2-23] have focused attention upon the importance of sample size and adequate maturity and power of studies, duration as opposed to dosage, the route of administration, and the relevant endpoints - whether these are relapse-free survival (RFS) or overall survival (OS). In a previous review [24] we divided oncologists into two groups: the optimistic ones, better known as the IFN supporters, and the pessimistic ones, or physicians who discount the results of IFN. For the first group, whose number of adherents has grown in recent years, HDI represents the standard therapy based on the initial ECOG and subsequent US Intergroup studies that confirmed RFS impact and in two trials, OS impact ${ }^{1}$, [25-27]. The latter group has stated that IFN should not be considered standard therapy for melanoma patients, since the gains in OS are relatively small, and the side effects (or cost) can not be justified in relation to these toxicities and expenses. Table 1 summarizes the most important studies of IFNbased adjuvant therapy in melanoma, with total numbers of enrolled patients.

After more than 20 years of research and clinical experience with IFN, it is now time to make some definitive conclusions in order to avoid eternal discussions regarding the issues of sample size, dosage, route and duration of therapy, in order to move forward in our field. For this purpose we surveyed the international literature starting with the meta-analysis published in 2006 [28] and dealing with the adjuvant treatment of high-risk melanoma, to incorporate current biological evidence regarding this molecule and its impact in vivo, so as to arrive at conclu-

Table I: Characteristics of the main phase III adjuvant trials in high-risk melanoma patients.

\begin{tabular}{|c|c|c|c|c|c|c|}
\hline $\begin{array}{l}\text { References } \\
\text { Intergroup Trial }\end{array}$ & AJCC Stage & \# Total Patients enrolled & Arms & \# Patients for arm & $\begin{array}{l}\text { RFS } \\
P \text { value }\end{array}$ & $\begin{array}{l}\text { OS } \\
P \text { value }\end{array}$ \\
\hline $\begin{array}{l}\text { Creagan et al. }(1995)^{54} \\
\text { NCCTG 83-7052 }\end{array}$ & II-III & 262 & 2 & $\begin{array}{l}\text { HDI I3I } \\
\text { Control I3I }\end{array}$ & 0.19 & 0.40 \\
\hline $\begin{array}{l}\text { Kirkwood et al. (1996)। } \\
\text { ECOG El } 684\end{array}$ & IIB-III & 287 & 2 & $\begin{array}{l}\text { HDI I } 43 \\
\text { Control I37 }\end{array}$ & 0.0023 & 0.0237 \\
\hline $\begin{array}{l}\text { Grob et al. }(1998)^{34} \\
\text { French CGM }\end{array}$ & $\| A B$ & 499 & 2 & $\begin{array}{l}\text { LDI } 253 \\
\text { Control } 246\end{array}$ & 0.035 & 0.059 \\
\hline $\begin{array}{l}\text { Pehamberger et al.(1998)58 } \\
\text { Austrian MMCG }\end{array}$ & $\| A B$ & 311 & 2 & $\begin{array}{l}\text { LDI I54 } \\
\text { Control I57 }\end{array}$ & 0.02 & n.d \\
\hline $\begin{array}{l}\text { Kirkwood et al. }(2000)^{25} \\
\text { ECOG-US Intergroup El } 690\end{array}$ & IIB-III & 642 & 3 & $\begin{array}{l}\text { HDI } 203 \\
\text { LDI } 203 \\
\text { Control } 202\end{array}$ & $\begin{array}{l}0.03^{*} \\
0.17^{* *}\end{array}$ & $\begin{array}{l}0.744^{*} \\
0.672^{* *}\end{array}$ \\
\hline $\begin{array}{l}\text { Kirkwood et al. }(2001)^{26} \\
\text { ECOG-US Intergroup } \\
\text { El694 }\end{array}$ & IIB-III & 774 & 2 & $\begin{array}{l}\text { HDI } 385 \\
\text { GM2/QS-2I } 389\end{array}$ & 0.006 & 0.04 \\
\hline $\begin{array}{l}\text { Cascinelli et al. }(2001)^{59} \\
\text { WHO I6 }\end{array}$ & III & 444 & 2 & $\begin{array}{l}\text { LDI } 218 \\
\text { Control } 208\end{array}$ & 0.50 & 0.72 \\
\hline $\begin{array}{l}\text { Cameron et al. }(2001)^{60} \\
\text { Scottish MG }\end{array}$ & II-III & 96 & 2 & $\begin{array}{l}\text { LDI } 47 \\
\text { Control } 49\end{array}$ & $>0.1$ & $>0.2$ \\
\hline $\begin{array}{l}\text { Hancock et al. }(2004)^{61} \\
\text { UKCCCR-MCG }\end{array}$ & IIB-III & 654 & 2 & $\begin{array}{l}\text { LDI } 338 \\
\text { Control } 336\end{array}$ & 0.3 & 0.6 \\
\hline $\begin{array}{l}\text { Kleeberg et al. }(2004)^{62} \\
\text { EORTC I887I }\end{array}$ & II-III & 423 & 3 & $\begin{array}{l}\text { UDI } 240 \\
\text { IFN } \gamma 244 \\
\text { Control } 244\end{array}$ & $\begin{array}{l}0.71^{\circ} \\
0.73^{\circ \circ}\end{array}$ & $\begin{array}{l}0.72^{\circ} \\
0.25^{\circ \circ}\end{array}$ \\
\hline $\begin{array}{l}\text { Kleeberg et al. }(2004)^{62} \\
\text { DKG-80 }\end{array}$ & II-III & 407 & 4 & $\begin{array}{l}\text { Iscador } 102 \\
\text { Control } 102\end{array}$ & 0.12 & 0.31 \\
\hline $\begin{array}{l}\text { Eggermont et al. }(2005)^{31} \\
\text { EORTC } 18952\end{array}$ & IIB-III & 1418 & 3 & $\begin{array}{l}\text { HID-IFN } 565 \\
\text { LID-IFN } 569 \\
\text { Control } 284\end{array}$ & $0.1^{*}$ & $0.2^{*}$ \\
\hline $\begin{array}{l}\text { Eggermont et al. }(2008)^{32} \\
\text { EORTC I899I }\end{array}$ & III & 1256 & 2 & $\begin{array}{l}\text { PEG-IFN } 627 \\
\text { Control } 629\end{array}$ & $\begin{array}{l}0.01 I^{\#} \\
0.107 \# \#\end{array}$ & 0.78 \\
\hline $\begin{array}{l}\text { Gogas et al. }(2007)^{33} \\
\text { He.Co.G }\end{array}$ & IIBC-III & 364 & 2 & $\begin{array}{l}\text { HDI I mos } 182 \\
\text { HDI I } 2 \text { mos } 182\end{array}$ & 0.94 & 0.51 \\
\hline
\end{tabular}

RFS: Relapse-free survival; OS: Overall survival; HDI: high-dose interferon; ULD-IFN: Ultra-low dose interferon; HID-IFN: high-intermediate dose interferon; LID-IFN: low-intermediate dose interferon. P value refers to comparison between HDI and control groups* or LDI and control**. P value refers to comparison between LID-IFN and control and reflects the Distant Metastases Free Survival (DMFS)*. P value refers to comparison between UDI and control ${ }^{\circ}$ or IFN $\gamma$ and control ${ }^{\circ}$. P value refers to Relapse-Free Survival\# and DMFS"\#. 
sions that may be useful for practitioners. Perhaps new evidence will serve as the most useful guidepost for further ventures in the world of adjuvant IFN.

\section{Meta-analysis}

Wheatley et al. [19] conducted a literature-based metaanalysis of randomized trials of adjuvant interferon versus observation in patients with high-risk melanoma. The collective analysis of these 12 trials allowed the authors to conclude that relapse-free survival (RFS) was improved with IFN (HR for recurrence, $0.83 ; 95 \%$ CI, 0.77-0.90 [P $<.000003]$ ), corresponding to a $17 \%$ reduction in the risk of recurrence. There was no clear survival benefit (HR for mortality, $0.93 ; 95 \% \mathrm{CI}, 0.85-1.02[P<.1])$. The authors concluded that the evidence for clinically worthwhile survival benefit is unconvincing, given a reduction in the risk of death that was $\leq 7 \%$, that would translate to an absolute reduction in mortality of $\sim 3 \%$ with a confidence interval that might include a reduction of $6 \%$ in mortality. That meta-analysis did not include the E1694 trial, which is the largest adjuvant trial ever conducted in the US. The data from that vaccine trial analyzed separately with data from the remaining two ECOG studies however did not yield further evidence of a survival benefit. Subgroup analyses conducted to examine dose-response relationships in this meta-analysis indicated a significant trend towards increasing RFS benefit with increasing dosage. In fact, there was evidence to support the argument that HDI is more effective than LDI with a borderline $\mathrm{p}$-value of $\mathrm{p}=$ .02 for the correlation of RFS with dose. However, the authors concluded that there was insufficient data to determine a dose-response relationship with HDI, as opposed to a lack of efficacy with LDI, and suggested that more data was needed to conclude whether IFN- $\alpha$ dose is important for OS.

Pirard et al. [29] conducted another literature-based metaanalysis of nine randomized trials of IFN versus observation in order to evaluate the effect of IFN- $\alpha$ on relapse rate (RR) and overall survival (OS). They reached similar conclusions to Wheatley et al., but noted improvement in the recurrence rate with interferon (odds ratio $0.74 ; 95 \% \mathrm{CI}$, 0.64-0.86) without improvement in OS. Subgroup analyses showed that overall for the range of stages, HDI and LDI decreased the RR (OR $=0.71,95 \% \mathrm{CI}=0.54-0.92$, and $\mathrm{OR}=0.76,95 \% \mathrm{CI}=0.63-0.91$, respectively), without an impact on OS.

A critical systematic review of the international literature performed by Verna et al. [30] evaluated randomized controlled trials of adjuvant treatment for high-risk melanoma patients to derive practice guidelines, including meta-analyses and reviews published between 1980 and 2004. Reported results showed that treatment with HDI consistently produced a significant improvement in
RFS. Both RFS and 2-year mortality rates were significantly improved: 2-year death rates were reduced to a risk ratio of 0.85 (95\% confidence interval, $0.73-0.99 ; P<.03$ ). The authors chose this endpoint because 2-year survival may represent a meaningful benchmark for high-risk melanoma patients in terms of recurrence. The authors concluded that considering and discussing HDI is a reasonable option in appropriate patients.

Wheatley et al. [19] encouraged collaboration between groups that had performed randomized trials of adjuvant IFN in melanoma to develop an individual patient data (IPD) meta-analysis in which longer follow-up could be included, considering that some published trial reports are from several years ago, thereby increasing the number of events available for analysis and hence the reliability of the analysis. At the American Society of Clinical Oncology meeting in 2007, Wheatly et al. [28] reported the results of an IPD meta-analysis of randomized trials utilizing IFN as adjuvant therapy in melanoma patients. The main purpose of this IPD meta-analysis was to assess the totality of current evidence and to improve the assessment of IFN in the adjuvant treatment of melanoma. Despite a previous meta-analysis, the E1694 trial of IFN versus GMK vaccine was included, and the authors noted that sensitivity analysis performed excluding and including this trial made no difference in the assessment of impact upon OS. There was a statistically significant benefit for IFN for event freesurvival (EFS): $\mathrm{OR}=0.87(\mathrm{CI}=0.81-0.93)$, but in contrast to the findings of an earlier meta-analysis by this group, no evidence was found for a difference according to dose $(p=0.2)$. Even more notably, there was no evidence of a difference according to duration of IFN ( $p=0.5)$. And most interestingly, there was a statistically significant benefit of IFN upon OS from this analysis ( $=0.008)$ : the OR for benefit was $0.90(\mathrm{CI}=0.84-0.97)$, with no evidence of any difference according to dose $(\mathrm{p}=0.8)$ or duration of IFN $(\mathrm{p}=0.9)$. This proportional survival advantage translates into an absolute benefit of at least 3\% (CI 1-5\%) at 5 years [28]. A subgroup analysis showed that patients with ulcerated primary melanoma had an even greater benefit from IFN (EFS: OR $=0.76$, OS: OR $=0.77$ ) by comparison with those without ulceration (EFS: $\mathrm{OR}=0.94$, OS: OR $=0.98$ ). They concluded that IPD meta-analysis provides evidence that adjuvant IFN significantly reduces the risk of relapse and improves the OS of high-risk melanoma, even if the absolute benefit is small, and not, as in this analysis, correlated with dose or duration of therapy. [28]

\section{Results of pending studies}

Critical reading of the major international randomized trials shows that short-term relapse risk reduction with IFN appears to be independent of dosage, while durable reduction of relapse and mortality in studies followed for 
intervals of 7 years and longer has been documented only with the high-dose regimen tested first in E1684 $[7,12,13,15,19,21,24]$. The EORTC 18952 trial results [31] suggest that IFN therapy at an intermediate 2-year window of time, prevents recurrence while on treatment. Prolonged IFN therapy improved RFS in this study, although the authors concluded that this regimen could not be recommended. Since LDI has been relatively welltolerated in comparison to HDI (grade 3-4 toxicity in about $10 \%$ vs. $70 \%$ of cases, respectively), prolonged LDI for more than 2 years was suggested as a reasonable option for melanoma patients, considering its cost-effectiveness. For these reasons, the international community has awaited mature results of the EORTC 18991 [32] trial. In fact, EORTC 18991, which compared pegylated-IFN (PEG-IFN) [induction phase of 8 weeks $(6 \mu \mathrm{g} / \mathrm{kg} /$ week $)$ with a maintenance phase of 5 years $(3 \mu \mathrm{g} / \mathrm{kg} /$ week) given subcutaneously] versus control, clarified the role of duration of therapy with IFN, and provided data upon a higher dosage of PEG-IFN and an attempted longer duration (5 years) of treatment, two issues that have been discussed at length during recent years.

The EORTC 18991 trial was undertaken to test the hypothesis that prolonged exposure to IFN through the use of newer PEG-coupled forms of IFN, given subcutaneously weekly have anti-angiogenic effects in stage III melanoma patients, where the primary endpoint chosen by the EORTC was distant metastasis-free survival (DMFS), and the secondary endpoint was overall survival (OS) [32]. However, for regulatory submission it was recommended that RFS be evaluated. The results obtained in 1,256 stage III melanoma patients show no significant impact of the regimen upon DMFS, and no impact upon the secondary goal of OS [DMFS and OS rates $(\mathrm{p}=0.107$, $\mathrm{HR}=0.88(95 \% \mathrm{CI}=0.75-1.03)$ and $\mathrm{p}=0.78, \mathrm{HR}=0.98$ $(95 \% \mathrm{CI}=0.82-1.16)$ respectively]; by contrast there was a significant reduction in hazard for relapse, with reduction of RFS rate $[\mathrm{p}=0.011, \mathrm{HR}=0.82(95 \% \mathrm{CI}=0.71-$ 0.96)] at 4 years median follow-up. Subgroup analysis showed improved impact of PEG-IFN upon RFS in stage III-N1 melanoma patients and in this subset an impact was also observed upon DMFS $[\mathrm{p}=0.016, \mathrm{HR}=0.73$ $(95 \% \mathrm{CI}=0.53-1.02)$ and $\mathrm{p}=0.03, \mathrm{HR}=0.75(95 \% \mathrm{CI}=$ 0.52-1.07) respectively], although there is no evidence of an impact upon OS $[\mathrm{p}=0.43, \mathrm{HR}=0.88(95 \% \mathrm{CI}=0.58-$ 1.33)]. Subset effects were noted for patients with primary tumor ulceration $[\mathrm{p}=0.006, \mathrm{HR}=0.59(95 \% \mathrm{CI}=0.35-$ $0.98)]$ as had earlier been reported in the meta-analysis of Wheatley et al. [2007] [28]. The trial employed two phases of differing dose intensities both administered subcutaneously (and neither yet possible to correlate to the original IV induction and SC maintenance phases of the FDAapproved HDI regimen), and an initial higher-dose intensity phase of 8 weeks: while the median duration of treat- ment during the first phase was 8 weeks, the median duration of maintenance therapy at the lower dosage of $\leq$ $6 \mathrm{ug} / \mathrm{kg} /$ dose was only 12 months and only $23 \%$ of patients were treated during the $4^{\text {th }}$ and $5^{\text {th }}$ years. These last results suggest that the EORTC 18991 trial failed to clarify the role of longer-term therapy with IFN. Unfortunately, given a suggested impact in the more favorable population of N1 (IIIA, AJCC) patients, this trial is still quite early in followup - and will be best interpreted when a maturity of 5-7 years has been reached.

Gogas et al. [33] have reported another important phase III study in 2007 in a trial that compared 1 month versus 1 year of a modified dosage regimen designed to determine whether the unique aspect of the three US Cooperative group trials that have shown durable impact upon RFS may lie in the use of IV induction with HDI. In this trial the dosage of IFN differed from the classical E1684, being reduced by $25 \%$ for the induction phase, and approximately $33 \%$ for the maintenance phase (arm A: IFN $15 \mathrm{MIU} / \mathrm{m}^{2} \mathrm{IV}$. for $5 / 7$ days weekly for 4 weeks; arm B: IFN $15 \mathrm{MIU} / \mathrm{m}^{2}$ IV for 5/7 days weekly for 4 weeks followed by maintenance dosage of $10 \mathrm{MIU}$ [total rather than per $\mathrm{m}^{2}$, three times a week for 48 weeks]. The trial enrolled 364 high-risk melanoma patients and reached a median follow-up of 51 months. The outcome for relapse and mortality was similar between the two arms, but given the numbers of patients accrued, this allows us to conclude at the 5\% significance level only that 3-year relapse-rates of arm A were not 15\% higher than the shorter treatment arm B ( $\delta=0.15$ at 3 years). An ongoing US Intergroup trial testing one month of induction therapy at the classical dosage of $20 \mathrm{MIU} / \mathrm{m}^{2} /$ day for 20 doses over 4 weeks vs. observation is more than half completed, and will require a total of 1420 patients to answer the question of whether treatment has a benefit upon relapsefree survival of $7.5 \%$ or more.

\section{Immunological evidence}

One of the unsolved questions remains - what is the mechanism of action of IFN? During the last 10 years we have had a number of studies that were generally underpowered, and where eligibility allowed inhomogeneous populations to be enrolled into clinical trials testing various dosages and durations of treatment. Clearly, larger trials offer more robust conclusions, and if trials demonstrate that the modality has an impact upon only some stage subsets, and not others, it may refine our application of this modality. Attention to the mechanism of action of IFN is likely to guide the improvement of this modality more than many other maneuvers. For example, one of the most interesting debates when the E1684 trial was published was whether HDI acted through a cytotoxic or immunological mechanism. At that time many oncologists leaned toward a cytotoxic mechanism of action 
rather than an immunological mechanism. Only the trial of the French Group [34] provided evidence for an immunological mechanism from their clinical findings. In fact, after the publication of the results of LDI treatment in low-intermediate-risk stage II melanoma patients, they demonstrated the existence of a subset of responsive patients [35] defined on the basis of elevated white blood cell (WBC) counts where more prolonged RFS was obtained. In the last few years several important immunological findings have added strong support for this hypothesis that the mechanism of action of IFN is immunomodulatory.

Moschos et al. [36] reported data from a neoadjuvant treatment study with HDI given according to the induction phase of the E1684 trial: after induction treatment in this study $11 / 20$ (55\%) stage IIIB melanoma patients showed objective regression of palpable regional lymph node disease, and 10/20 (50\%) patients were disease free after a median follow-up of 18.5 months. An important immunological finding regarding response to HDI treatment was that the number of mononuclear lymphocytes and dendritic cells were increased in the tumor tissue at 4 weeks of treatment among responders. This correlation of response with increased tumor-infiltrating $\mathrm{CD}^{+}$and CD $11 \mathrm{c}^{+}$cells, and decreased CD83+ cells suggests an indirect immunomodulatory mechanism of action for this therapy [36].

Additional strong evidence for an indirect immunomodulatory mechanism of action has come from the Hellenic Oncology Group trial of Gogas et al. [37], which showed that the development of clinical and serological manifestations of autoimmunity, including autoantibodies to and clinical manifestations of autoimmunity in melanoma patients treated with HDI (26\% of the total), correlates with a better RFS and OS. In fact, the Hellenic Group found only 2 deaths in 52 melanoma patients with serologic or clinical evidence of the development of autoimmunity during treatment, while there were 80 deaths among 148 patients without such evidence of autoimmunity $(\mathrm{p}<0.001)$.

This phenomenon has been further explored by the Eastern Cooperative Oncology Group in a study reported by Stuckert et al. [38] in 2007: a correlation was shown between the development of autoantibodies among HDItreated patients, and improvement of RFS and OS - but in this retrospective study only serological and not clinical manifestations were possible to evaluate. These data showed a strong trend $(\mathrm{p}=.06)$ for correlation of the serological development of autoantibodies during HDI and melanoma relapse and mortality - extending the work of Gogas et al., demonstrating clinical benefit with immunomodulation and induction of autoimmunity. The induction of autoantibodies may be a useful surrogate marker for monitoring the efficacy of IFN therapy.

The association between a better outcome and the appearance of autoimmune phenomena was previously demonstrated in early studies of IL-2 where thyroid autoimmune responses were shown to be strong correlates of therapeutic benefit in advanced disease, and in more recent studies utilizing anti-cytotoxic T-lymphocyte antigen 4 (CTLA-4) antibodies that act through releasing inhibitory functions mediated by this molecule in $\mathrm{T}$ cells [39-42]. CD4+ $\mathrm{T}$ lymphocytes that express high levels of CD25 on their surface and the specific marker FoxP3, have shown suppressive functions upon $\mathrm{T}$ cells reactive with self antigens. The possibility that the Treg cells could influence the clinical outcome of cancer patients has been hypothesized on the basis of their increased number in many cancers [43-48].

Viguier et al. [49] described increased numbers of Tregs in peripheral blood (PB) of melanoma patients and their presence in lymph nodes containing metastatic disease, capable of inhibiting the effector functions of the immune response in situ. Cesana et al. [50] reported increased basal levels of Treg in PB of melanoma and renal cell carcinoma (RCC) compared to healthy donors. Our preliminary results [51] support a possible role of HDI in relation to Treg, decreasing their number in $\mathrm{PB}$ with the consequent possibility of potentiation of immune responses. In fact, among 8 consecutive patients treated with HDI as a neoadjuvant or adjuvant therapy, we tested on days 0,8 , 15, 22 and 29 (after the HDI induction phase iv) the level of Treg cells in the PBMC. Our findings showed that circulating Treg levels decreased in 7 of the 8 patients $(87.5 \%)$ with a median value for the drop in reduction in the circulating fraction of Treg that was $1.7 \%$ (range $0.3-4,8 \%$ ) (Figure 1). Moreover, in the only patient in which we did not observe a decrease of Treg, HDI treatment was discontinued after 2 weeks for grade 3 hepatotoxicity. This provides further evidence to support the concept of an indirect mechanism of immunomodulatory action for HDI. There is a large need for further studies that correlate clinical outcome and changes in Treg before reaching any conclusions.

Molecular correlates of action for IFN would be of great use, and several candidates exist in the JAK-STAT pathway through which IFN signaling occurs. The Janus-activated kinase (JAK)/signal transducers and activators of transcription (STAT) pathway of IFN signaling are important for immunoregulation and tumor progression. Wang et al. [52] reported results in the setting of a prospective neoadjuvant trial of HDI [36] demonstrating the reciprocal effects of HDI upon STAT1 and STAT3, which appear to operate jointly as mediators of IFN effects. It has been postulated that these may be best assessed in the balance of 
A

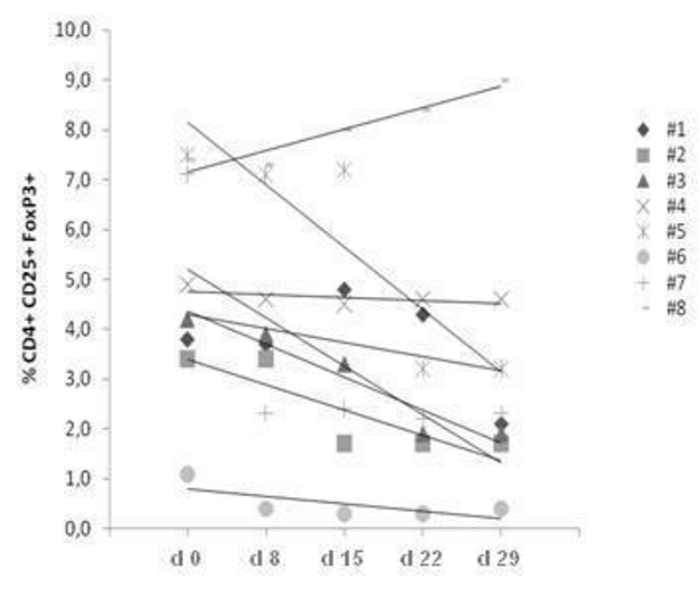

B

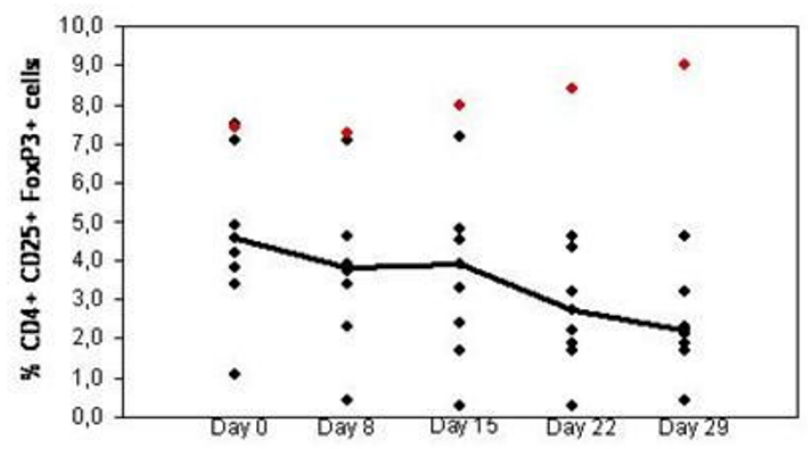

C

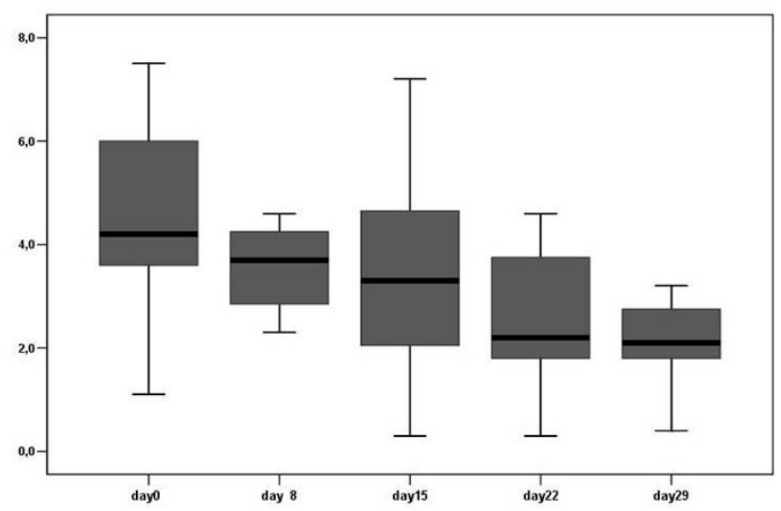

Figure I

A-B-C. Levels of circulating Treg cells (CD4+CD25+FoxP3+) in the blood of melanoma patients during the four weeks of HDI IV induction therapy. The peripheral blood assays have been performed at the start of each week of treatment (Day 0, 8, I5, 22) and after the last week (on Day 29). (A) Trend in a single patient; (B) trend of the average value of Treg cells during HDI IV treatment; (C) Boxplot summarizing the data observed in the cohort of patients during the initial 4 weeks of treatment. 
pSTAT1 and PSTAT3. STAT1 plays a prominent role in the effector immune response, whereas STAT3 is implicated in tumor progression and down-regulation of the response to type I IFNs. HDI was found to up-regulate pSTAT1, whereas it down-regulates pSTAT3 and total STAT3 levels in both tumor cells and lymphocytes. Higher pSTAT1/pSTAT3 ratios in tumor cells pretreatment were associated with longer overall survival $(\mathrm{P}=0.032)$. The pSTAT1/pSTAT3 ratios were augmented by HDI both in melanoma cells $(P=0.005)$ and in lymphocytes $(P=$ 0.022). Of the immunologic mediators and markers tested, only TAP2 was augmented by HDI. Thus, Wang et al. demonstrated that HDI significantly modulates the balance of STAT1/STAT3 in tumor cells and host lymphocytes, leading to up-regulation of TAP2 and augmented host antitumor response. Moreover, the pSTAT1/ pSTAT3 ratio in tumor cells at baseline could serve as a predictor of clinical outcome, and the modulation of this ratio could serve as a predictor of therapeutic effect.

Yurkovetsky et al. [53] utilized a multiplexed cytokine assay in order to analyze differences in serum concentrations of 29 different cytokines, and angiogenic and growth factors in melanoma patients and healthy controls. For this purpose serum samples were analyzed from 179 melanoma patients before HDI or vaccine adjuvant treatment and from 378 healthy controls. A statistically significant increase in concentrations of 15 biomarker proteins (IL-1 $\alpha$, IL-1 $\beta$, IL-6, IL-8, IL-12p40, IL-13, GCS-F, MCP-1, MIP-1 $\alpha$, MIP-1b, IFN $\alpha$, TNF $\alpha$, EGF, VEGF, and TNFRII) was found in the sera of melanoma patients compared with age- and sex-matched healthy controls $(\mathrm{P}<$ $0.05-\mathrm{P}<0.001)$. These data showed that melanoma patients have a significantly different pattern of expression for multiple serum cytokines compared with healthy individuals. Moreover, HDI therapy induced significant changes in the serum concentrations of multiple cytokines. HDI therapy decreased levels of angiogenic and growth factors (VEGF, EGF, HGF), whereas expression of IP-10, IFN- $\alpha$, MCP-1, IL-12p40, soluble TNFR-I, TNFR-II, and IL-2R were significantly increased in the serum evaluated 3 months post initiation of HDI treatment. These changes observed 3 months after HDI treatment did not correlate with outcome (treatment benefit) but it remains unclear whether earlier or later changes in cytokine concentrations might correlate with RFS. Of great interest, these data from the University of Pittsburgh show that pretreatment levels of the proinflammatory cytokines IL$1 \alpha$, IL- $1 \beta$, IL- 6 , TNF $\alpha$, and the chemokines MIP- $1 \alpha$ and MIP-1 $\beta$ were significantly higher in the serum of patients who were treated with HDI and had RFS longer than 5 years, compared with those who relapsed earlier. No such correlation existed between these pro-inflammatory cytokines and the outcome of patients treated with the GMK vaccine. In fact, melanoma patients with the highest levels of these cytokines had the highest rates of RFS at intervals of $>1$ and $>5$ years, whereas patients with the lowest levels of these cytokines tended to have RFS of $<1$ year. It thus appears that the baseline cytokine milieu of the patient prior to treatment with HDI may predict the susceptibility to benefit from HDI.

A final recent study upon STAT1 and T cell signaling in the blood lymphocytes of patients with melanoma is noteworthy, and may allow us to understand the treatment benefit of HDI, that has not been seen with other regimens of IFN that do not achieve high circulating levels of IFN in the blood. The group of Lee et al. [54] have studied $\mathrm{T}$ cell signaling defects known to be associated with advanced melanoma, and that provide some of the impetus to consider the evaluation of new therapies in patients who do not have such far-advanced disease (as in the adjuvant setting). These investigators have used phosphoflow analyses for STAT1 phosphorylation to document a surprisingly high frequency of $\mathrm{T}$ cell signaling defects in the PB lymphocytes of patients with advanced melanoma ( $30 \%)$. Normalization of this defect was found by in vitro exposure of the PB lymphocytes of these patients to high concentrations of IFN, such as would be expected to be achieved by the administration of $20 \mathrm{MU} / \mathrm{m}^{2}$ during induction therapy using the classical regimen of HDI, but not by exposure to lower concentrations.

\section{Conclusion}

After the most recent meta-analysis and the reports of the latest results of ongoing clinical trials testing new variations on adjuvant treatment for high-risk patients, what more do we know and what can we conclude? Recent announcements regarding the negative results for the EORTC 18961 trial (unpublished) that compared GMK vaccination with observation [OS worse with GMK ( $\mathrm{p}<$ $0.02)]$, indicate that there may be less certainty in regard to the results of E1694 than previously. We, however, are strongly convinced of the contrary!

First of all, regarding the statistical investigations we have affirmed [24] that "transitive properties" do not apply for medical trials. It is a fundamental mistake to consider GMK vaccination with Tay Sachs Brain derived GM2 and Bovine or Rabbit Brain derived GM2 equivalents to synthetic GM2 as performed in the EORTC 18961 trial. In fact, in E1694 bovine brain or rabbit brain-derived GM2 has not formally been established to be immunologically equivalent to the synthetic GM2 utilized in the EORTC 18961. Comparisons of the data observed for these fundamentally different kinds of GM2 vaccinations are as different as the Salk formalinized Polio virus vaccine and the Sabin live vaccine. So the murky nature of the vaccination studies with GM2 should not compromise the 25 years of incremental understanding that has emerged in relation 
to IFN, and the spate of recent biological findings that have clarified the role of IFN in the adjuvant setting.

The issue of IFN treatment duration has been addressed in the recent Wheatley report [28]. It was apparent that adjuvant IFN significantly reduces the risk of relapse and improves OS (even if the absolute benefit of the survival increment is relatively small) and additionally there was no evidence that such a benefit is duration-dependent.

The EORTC 18991 trial failed in its original stated purpose, which was to evaluate the importance of prolonged durations of treatment to 5 years, on the basis of the availability of a new formulation of PEG-IFN. In fact, the median duration of treatment was only 14.9 months barely 3 months past the 12 month E1684 regimen that $90 \%$ of non-relapsing patients in E1694 received. Ultimately, only $23 \%$ of stage III melanoma patients were treated for 4-5 years, so this trial does not permit any conclusions regarding the impact of longer durations of treatment. Moreover, it is not possible to make any comparison between HDI and PEG-IFN because, IFN $\alpha 2 \mathrm{~b}$ (used for the trials of HDI) and PEG-IFN are two different drugs administered by very different routes (IV and SC. respectively) for which there are few rigorous data based upon careful studies comparing the two of these agents for any of the relevant immunological and anti-tumor endpoints.

Secondly, in Table 2 all of the recent immunological findings correlated with HDI are summarized. It represents the first time in the history of adjuvant IFN therapy that we have strong evidence that HDI works though indirect immunological mechanisms. These data in support of the new formulation of PEG-IFN are still quite incomplete. These findings relate in general to the effects of the induction phase of HDI suggesting a critical role of the pharmacokinetics of HDI given IV. The induction phase of HDI administered according to E1684 [1] distinguished this regimen from the Mayo NCCTG regimen of 3 months intramuscularly (i.m.) with high-dose IFN as reported by Creagan (IFN- $\alpha 2 a 20 \mathrm{MU} / \mathrm{m}^{2} \mathrm{i}$.m. tiw $\times 3$ months) [55] which failed to alter disease outcome. While this regimen has been considered similar to the E1684 IV. induction phase, it has never been shown to achieve the blood levels of $>10,000 \mathrm{u} / \mathrm{ml}$ that have been associated with E1684 IV dosing. These findings stress the importance of the IV. route of administration and add a caveat regarding the difficulties in attempting to make comparisons between ECOG HDI and the EORTC PEG-IFN regimen, which must be considered a challenge for the future.

The Hellenic Cooperative Group study [33] has utilized a further variation upon the E1684 regimen, to compare 1 month and 12 months of treatment, and the lack of differences between the results of IV treatment with $75 \%$ of the IV induction dosage stipulated in E1684, and this induction, added to a maintenance regimen that gave $10 \mathrm{MIU}$ per dose rather than $10 \mathrm{MIU} / \mathrm{M} 2$ for 11 months, supports the hypothesis that the IV induction phase of treatment is of paramount importance. The ongoing E1697 trial (comparing 1 month HDI versus observation) and the Italian Melanoma Inter-group trial (IMI - Mel.A) [56] (which compares intensified IV HDI versus the E1684 schedule) as well as the German-Austrian-Swiss DeCOG trial testing repetitive induction vs. the E1684 schedule) will give us additional information.

In Table 3 we summarize the known absolute benefit at 5 years for adjuvant therapy for several common cancers. The recent meta-analysis by Wheatley et al. [28] for a multitude of regimens, most of which have never been suggested to induce durable remission or prolonged survival, have in aggregate shown an absolute benefit for survival at 5 years of $\sim 3 \%$ (with CI from 1-5\%). Classical chemotherapy for cancers reported in Table 3 shows an absolute benefit at 5 years that ranges from $4 \%$ to $9 \%$ with toxicity that is not trivial (i.e. lung and ovarian cancer).

These considerations together with recent findings that illuminate the immunological nature of the therapeutic mechanism of HDI suggest that we ought not to change our attitude about the role of adjuvant high-dose IFN in high-risk melanoma patients. It is time to deploy the therapy we have had for more than a decade, and to make individual (patient oriented) conclusions in regard to the benefit of HDI. IFN works and gives an absolute survival benefit at 5 years that may be as much as $5 \%$. This benefit is not far from the results of uncontested therapies for other kinds of cancer. Moreover, if we can confirm the role of the induction phase of high-dose IV IFN administered during the first one month of the effective schedule, phy-

Table 2: Recent evidence for indirect immunomodulatory mechanisms of HDI

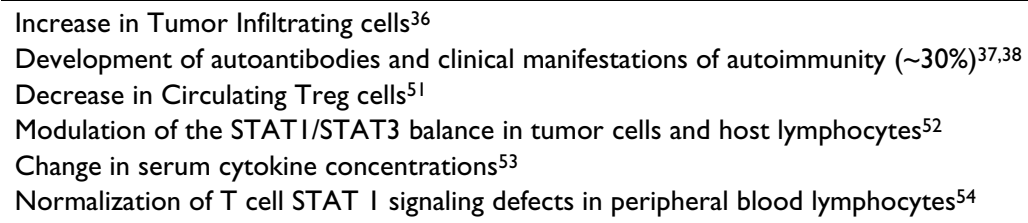


Table 3: Absolute benefit at 5 years of the most important adjuvant treatments for cancer

\begin{tabular}{|c|c|c|}
\hline Adjuvant Regimen & Type of Cancer & \% Absolute Benefit at 5-years \\
\hline IFN vs none 28 & Melanoma & $>3.0$ \\
\hline CMF like CT vs none 63 & Breast & 4.7 \\
\hline Anthracycline based CT vs CMF like $C^{63}$ & Breast & 3.3 \\
\hline FolFox vs none ${ }^{64}$ & Colo-rectal & 5.9 \\
\hline Platinum-based CT vs none ${ }^{65}$ & Lung & 4.1 \\
\hline Platinum-based CT vs none 66,67 & Ovarian & 7-9 \\
\hline
\end{tabular}

sicians could offer patients an effective treatment with very manageable and short term toxicity that would compare favorably with other adjuvant regimens for unrelated solid tumors.

Our efforts should now be focused upon determining the scientific basis of action for this modality, and those patients who benefit the most from IFN therapy, as well as how to overcome resistance to further enhance efficacy of IFN. Specifically, it is time to test new combinations with HDI in the advanced and adjuvant disease settings, starting with recent immunological findings. This will include use of neoadjuvant approaches, or the more intelligent evaluation of sentinel nodes in relation to the determinants of therapeutic benefit for IFN; second is to increase our knowledge regarding the critical biological determinants in every adjuvant trial, such as the induction of autoantibodies, and the definition of immunogenetic factors that can predict the susceptibility to autoimmunity. The real objective of future efforts will ultimately be to build a scientific basis for individualized therapy based upon the knowledge of the unique molecular features and immune system of each melanoma patient [57]. What to do in the mean time? We suggest that HDI administered in the conventional E1684 trial schedule is the most reasonable approach, and this clearly can be modified according to toxicity, and at least should include the initial component of IV induction along with careful assessment of the molecular and immunological aspects that may inform future development and refinements of this regimen.

\section{Competing interests}

JMK is as a consultant for Eleos Inc, serves on the Speakers' Bureau for Schering Plough Corp and receives research grant support from Pfizer, Bristol Myers Squibb, MedImmune, GlaxoSmithKline and AstraZeneca.

\section{Authors' contributions}

JMK and PA both 1) made intellectual contributions and participated in the acquisition, analysis and interpretation of data; 2) have been involved in drafting the manuscript; and 3) have given final approval of the version to be published.

\section{References}

I. Kirkwood JM, Strawderman MH, Ernstoff MS, Smith TJ, Borden EC, Blum RH: Interferon alfa-2b adjuvant therapy of high-risk resected cutaneous melanoma: The Eastern Cooperative Oncology Group trial EST I 684. J Clin Oncol 1996, I 4:7-I7.

2. Olhoffer IH, Bolognia JL: What's new in the treatment of cutaneous melanoma? Semin Cutan Med Surg 1988, I 7:96-107.

3. Barth A, Morton DL: The role of adjuvant therapy in melanoma management. Cancer 1995, 75:726-34.

4. Johnson TM, Smith JM II, Nelson BR, Chang A: Current therapy for cutaneous melanoma. J Am Acad Dermatol 1995, 32:689-707.

5. Cook JC, Zitelli JA: Treating patients with melanoma with interferon. Arch Dermatol 1997, I 33:387-9.

6. Borden EC, Smith TJ: Melanoma: adjuvant therapy with interferons. Am Soc Clin Oncol Ed Book 1999:120-5.

7. Ascierto PA, Palmieri G: Adjuvant therapy of cutaneous melanoma [letter]. The Lancet 1999, 353:328.

8. Whittaker S: Adjuvant therapy in melanoma. Clin Exp Dermatol 2000, 25:497-502.

9. Sanjiv SA, Kirkwood JM: Update on the role of adjuvant interferon for high risk melanoma. Forum 2000, 1 0:230-9.

10. Eggermont AMM: Adjuvant therapy of malignant melanoma and the role of sentinel node mapping. Recent Results Cancer Res 2000, I 57:178-89.

II. Kimyai-Asadi A, Usman A: The use of interferon alfa as adjuvant therapy for advanced cutaneous melanoma: The need for more evidence. J Am Acad Dermatol 2000, 43:708-II.

12. Hancock BW, Harris S, Wheatley K, Gore M: Adjuvant interferon alpha in malignant melanoma: Current status. Cancer Treat Rev 2000, 26:81-9.

13. Eggermont AMM: The role interferon-alpha malignant melanoma remains to be defined. Eur J Cancer 200I, 37:2147-53.

14. Middleton $\mathrm{MR}$, Thatcher $\mathrm{N}$ : Adjuvant interferon in melanoma: A resurrection? $\mathrm{Br} J$ Cancer 200I, 84: I| $4 \mid-2$.

15. Ascierto PA, Palmieri G, Daponte A, Melucci MT, Satriano RA, Mozzillo N, Castello G: Adjuvant therapy of melanoma: what's new? Melanoma Res 2002, I 2:293-6.

16. Kirkwood JM, Ibrahim JG, Sondak VK, Ernstoff MS, Ross M: Interferon alfa-2a for melanoma metastases. The Lancet 2002, 359:978-9.

17. Lens $M B$, Dawes $M$ : Interferon alpha therapy for malignant melanoma: A systematic review of randomised controlled trials. J Clin Oncol 2002, 20:1818-25.

18. Kefford RF: Adjuvant therapy of cutaneous melanoma: The interferon debate. Ann Oncol 2003, I 4:358-65.

19. Wheatley K, Ives N, Hancock BW, Gore M, Eggermont A, Suciu S: Does adjuvant interferon- $\alpha$ for high risk melanoma provide a worthwhile benefit? A metaanalysis of the randomised trials. Cancer Treat Rev 2003, 29:241-52.

20. Sabel MS, Sondak VK: Pros and cons of adjuvant interferon in the treatment of melanoma. Oncologist 2003, 8:45I-8.

21. Eggermont AM, Punt CJ: Does adjuvant systemic therapy with interferon-alpha for stage II-III melanoma prolong survival? Am J Clin Dermatol 2003, 4:53 I-6.

22. Pawlik TM, Sondak VK: Malignant Melanoma: Current state of primary and adjuvant treatment. Crit Rev Oncol Hematol 2003, 45:245-64.

23. Kirkwood JM, Manola J, Ibrahim j, Sondak V, Ernstoff MS, Rao U: A Pooled Analysis of Eastern Cooperative Oncology Group 
and Intergroup Trials of Adjuvant High-Dose Interferon for Melanoma. Clin Cancer Res 2004, 10:1670-7.

24. Ascierto PA, Scala S, Ottaiano A, Simeone E, de Michele I, Palmieri G, Castello G: Adjuvant treatment of malignant melanoma: where are we? Crit Rev Oncol Hematol 2006, 57:45-52.

25. Kirkwood JM, Ibrahim JG, Sondak VK, Richards J, Flaherty LE, Ernstoff MS, Smith TJ, Rao U, Steele M, Blum RH: High- and low-dose interferon alfa-2b in high-risk melanoma: First analysis of Intergroup trial EI690/S9 I I //C9 I 90. J Clin Oncol 2000, 18:2444-58.

26. Kirkwood JM, Ibrahim JG, Sosman JA, Sondak VK, Agarwala SS, Ernstoff MS, Rao U: High-dose interferon alfa 2-b significantly prolongs relapse-free and overall survival compared with the GM2-KLH/QS-2I vaccine in patients with resected stage IIBIII melanoma: resilts of intergroup trial El694/S95/2/ C50980 I. I Clin Oncol 200I, 19:2370-80.

27. Kirkwood JM, Ibrahim J, Lawson DH, Atkins MB, Agarwala S, Collins K, Mascari R, Morrissey DM, Chapman PB: High-dose interferon $\alpha-2 b$ does not diminish antibody response to $G M 2$ vaccination in patients with resected melanoma: results of the Multicenter Eastern Cooperative Oncology Group Phase II Trial E2696. J Clin Oncol 200I, 19:1430-6.

28. Wheatley K, Ives N, Eggermont A, Kirkwood J, Cascinelli N, Markovic SN, Hancock B, Lee S, Suciu S, on behalf of International Malignant Melanoma Collaborative Group: Interferon- $\alpha$ as adjuvant therapy for melanoma: An individual patient data meta-analysis of randomised trials [abstract]. Proc Am Soc Clin Oncol 2007, 25:478S.

29. Pirard D, Heenen M, Melot C, Vereecken P: Interferon alpha as adjuvant postsurgical treatment of melanoma: a meta-analysis. Dermatology 2004, 208:43-8.

30. Verma S, Quirt I, McCready D, Bak K, Charette M, Iscoe N: Systematic review of systemic adjuvant therapy for patients at high risk for recurrent melanoma. Cancer 2006, 106: | 43 I-42.

31. Eggermont AM, Suciu S, MacKie R, Ruka W, Testori A, Kruit W, Punt C], Delauney M, Sales F, Groenewegen G, Ruiter DJ, Jagiello I, Stoitchkov K, Keilholz U, Lienard D, EORTC Melanoma Group: Post-surgery adjuvant therapy with intermediate doses of interferon alfa $2 b$ versus observation in patients with stage IIb/III melanoma (EORTC 18952): randomised controlled trial. The Lancet 2005, 366: II89-96.

32. Eggermont AM, Suciu S, Santinami M, Testori A, Kruit WH, Marsden J, Punt CJ, Salès F, Gore M, Mackie R, Kusic Z, Dummer R, Hauschild A, Musat E, Spatz A, Keilholz U, EORTC Melanoma Group: Adjuvant therapy with pegylated interferon alfa- $2 b$ versus observation alone in resected stage III melanoma: final results of EORTC I899 I a randomised phase III trial. Lancet 2008, 372: I 17-26.

33. Gogas H, Dafni U, Bafaloukos D, Polyzos A, Kokkalis G, Kalofonos HP, Fountzilas G, Skarlos D, Tsoutsous D, Pectasides D: A randomized phase III trial of I month versus I year adjuvant highdose interferon alfa-2b in patients with resected high risk melanoma [abstract]. Proc Am Soc Clin Oncol 2007, 25:473S.

34. Grob JJ, Dreno B, de la Salmoniere P, Delaunay M, Cupissol D, Guillot B, Souteyrand P, Sassolas B, Cesarini IP, Lionnet S, Lok C, Chastang $C$, Bonerandi JJ: Randomised trial of interferon $\alpha-2 a$ as adjuvant therapy in resected primary melanoma thicker than 1.5 $\mathrm{mm}$ without clinically detectable node metastases. The Lancet 1998, 35 I:1905-10.

35. de La Salmoniere P, Grob J], Dreno B, Delaunay M, Chastang C: White Blood Cell Count: A Prognostic Factor and Possible Subset Indicator of Optimal Treatment with Low-Dose Adjuvant Interferon in Primary Melanoma. Clin Cancer Res 2000, 6:47|3-8.

36. Moschos SJ, Edington HD, Land SR, Rao UN, Jukic D, Shipe-Spotloe J, Kirkwood JM: Neoadjuvant Treatment of Regional Stage IIIB Melanoma With High-Dose Interferon Alfa-2b Induces Objective Tumor Regression in Association With Modulation of Tumor Infiltrating Host Cellular Immune Responses. J Clin Oncol 2006, 24:3 I64-7.

37. Gogas H, loannovich J, Dafni U, Stavropoulou-Giokas C, Frangia K, Tsoutsos D, Panagiotou P, Polyzos A, Papadopoulos O, Stratigos A, Markopoulos C, Bafaloukos D, Pectasides D, Fountzilas G, Kirkwood JM: Prognostic Significance of Autoimmunity during Treatment of Melanoma with Interferon. N Engl J Med 2006, 354:709-18.

38. Stuckert JJ, Tarhini AA, Lee S, Sander C, Kirkwood JM: Interferon alfa-induced autoimmunity and serum $\mathrm{S} I 00$ levels as predic- tive and prognostic biomarkers in high-risk melanoma in the ECOG-intergroup phase II trial E2696 [abstract]. Proc Am Soc Clin Oncol 2007, 25:473S.

39. Phan GQ, Yang JC, Sherry RM, Hwu P, Topalian SL, Schwartzentruber DJ, Restifo NP, Haworth LR, Seipp CA, Freezer LJ, Morton KE, Mavroukakis SA, Duray PH, Steinberg SM, Allison JP, Davis TA, Rosenberg $\mathrm{SA}$ : Cancer regression and autoimmunity induced by cytotoxic $T$ lymphocyte-associated antigen 4 blockade in patients with metastatic melanoma. Proc Natl Acad Sci USA 2003, 100:8372-7.

40. Sanderson K, Scotland R, Lee P, Liu D, Groshen S, Snively J, Sian S, Nichol G, Davis T, Keler T, Yellin M, Weber J: Autoimmunity in a phase I trial of a fully human anti-cytotoxic T-lymphocyte antigen-4 monoclonal antibody with multiple melanoma peptides and Montanide ISA 5 I for patients with resected stages III and IV melanoma. J Clin Oncol 2005, 23:74I-50.

41. Dranoff G: CTLA-4 blockade: unveiling immune regulation. J Clin Oncol 2005, 23:662-4.

42. Ribas A, Bozon VA, Lopez-Berestein G, Pavlov D, Reuben JM, Parker CA, Seja E, Glaspy JA, Gomez-Navarro J, Camacho LH: Phase I trial of monthly doses of the human anti-CTLA4 monoclonal antibody CP-675, 206 in patients with advanced melanoma [abstract]. Proc Am Soc Clin Oncol 2005, 23:7I6s.

43. Liyanage UK, Moore TT, Joo HG, Tanaka Y, Herrmann V, Doherty G, Drebin JA, Strasberg SM, Eberlein TJ, Goedegebuure PS, Linehan DC: Prevalence of regulatory $T$ cells is increased in peripheral blood and tumor microenvironment of patients with pancreas or breast adenocarcinoma. J Immunol 2002, 169:2756-61.

44. Woo EY, Yeh H, Chu CS, Schlienger K, Carroll RG, Riley JL, Kaiser $L R$, June $\mathrm{CH}$ : Cutting edge: Regulatory $\mathbf{T}$ cells from lung cancer patients directly inhibit autologous $\mathbf{T}$ cell proliferation. Immunol 2002, 168:4272-6.

45. Ichihara $F$, Kono K, Takahashi $A$, Kawaida $H$, Sugai $H$, Fujii $H$ : Increased populations of regulatory $T$ cells in peripheral blood and tumor-infiltrating lymphocytes in patients with gastric and esophageal cancers. Clin Cancer Res 2003, 9:4404-8.

46. Ormandy LA, Hillemann T, Wedemeyer $H$, Manns MP, Greten TF, Korangy F: Increased populations of regulatory $T$ cells in peripheral blood of patients with hepatocellular carcinoma. Cancer Res 2005, 65:2457-64.

47. Sasada T, Kimura M, Yoshida $Y$, Kanai M, Takabayashi $A$ : $\mathrm{CD4}^{+} \mathrm{CD25} 5^{+}$regulatory $\mathrm{T}$ cells in patients with gastrointestinal malignancies: Possible involvement of regulatory $T$ cells in disease progression. Cancer 2003, 98: 1089-99.

48. Curiel TJ, Coukos G, Zou L, Alvarez X, Cheng P, Mottram P, Evdemon-Hogan M, Conejo-Garcia JR, Zhang L, Burow M, Zhu Y, Wei S, Kryczek I, Daniel B, Gordon A, Myers L, Lackner A, Disis ML, Knutson KL, Chen L, Zou W: Specific recruitment of regulatory $\mathbf{T}$ cells in ovarian carcinoma fosters immune privilege and predicts reduced survival. Nat Med 2004, 10:942-9.

49. Viguier M, Lemaitre F, Verola O, Cho MS, Gorochov G, Dubertret L, Bachelez H, Kourilsky P, Ferradini L: Foxp3 expressing CD4+CD25(high) regulatory $T$ cells are overrepresented in human metastatic melanoma lymph nodes and inhibit the function of infiltrating T cells. J Immunol 2004, 173:1444-53.

50. Cesana GC, DeRaffele G, Cohen S, Moroziewicz D, Mitcham J, Stoutenburg J, Cheung K, Hesdorffer C, Kim-Schulze S, Kaufman HL: Characterization of CD4+CD25+ Regulatory $T$ Cells in Patients Treated With High-Dose Interleukin-2 for Metastatic Melanoma or Renal Cell Carcinoma. J Clin Oncol 2006, 24: I 169-77.

5I. Simeone E, Napolitano M, Mauro F, Palmieri G, Ridolfi R, Riccobon A, Petrini M, De Rosa V, Satriano RA, Di Martino S, Nicoletti G, Gentilcore G, Capone M, Calemma R, Loddo C, Talamanca AR, Caracò C, Castello G, Ascierto PA: Blood reduction of circulating regulatory $\mathrm{T}$ cell (Treg) by intra venous High Dose Interferon treatment in melanoma matients: preliminary results. In Proceeding of the Fourth Research Meeting on Melanoma: I0-II May 2007; Milan, Italy IEO-European Institute of Oncology. Milano; 2007.

52. Wang W, Edington HD, Rao UN, Jukic DM, Land SR, Ferrone S, Kirkwood JM: Modulation of signal transducers and activators of transcription $I$ and 3 signaling in melanoma by high-dose IFNalpha2b. Clin Cancer Res 2007, I 3:|523-3I.

53. Yurkovetsky ZR, Kirkwood JM, Edington HD, Marrangoni AM, Velikokhatnaya L, Winans MT, Gorelik E, Lokshin AE: Multiplex 
analysis of serum cytokines in melanoma patients treated with interferon-alpha2b. Clin Cancer Res 2007, 13:2422-8.

54. Critchley-Thorne RJ, Yan N, Nacu S, Weber J, Holmes SP, Lee PP. Down-regulation of the interferon signaling pathway in $T$ lymphocytes from patients with metastatic melanoma. PLOS Med 2007, 4: el76.

55. Creagan ET, Dalton RJ, Ahmann DL, Jung SH, Morton RF, Langdon RM Jr, Kugler J, Rodrigue LJ: Randomized, surgical adjuvant clinical trial of recombinant interferon alfa-2 $a$ in se lected patients with malignant melanoma. J Clin Oncol 1995, 13:2776-83.

56. Chiarion-Sileni V, Del Bianco P, Romanini A, Guida M, Paccagnella A, Dalla Palma M, Naglieri E, Ridolfi R, Silvestri B, Michiara M, De Salvo $\mathrm{GL}$ : Tolerability of intensified intravenous interferon alfa-2b versus the ECOG 1684 schedule as adjuvant therapy for stage III melanoma: a randomized phase III Italian Melanoma Inter-group trial (IMI - Mel.A). BMC Cancer 2006, 6:44.

57. Palmieri G, Casula M, Ascierto PA, Tanda F, Cossu A: Molecular classification of patients with malignant melanoma for new therapeutic strategies. J Clin Oncol 2007, 25:e20-I.

58. Pehamberger H, Soyer HP, Steiner A, Kofler R, Binder M, Mischer P, Pachinger W, Auböck J, Fritsch P, Kerl H, Wolff K: Adjuvant interferon alfa-2a treatment in resected primary stage II cutaneous melanoma. J Clin Oncol 1998, 16:1425-9.

59. Cascinelli N, Belli F, MacKie RM, Santinami M, Bufalino R, Morabito A: Effect of long-term adjuvant therapy with interferon alpha$2 a$ in patients with regional node metastases from cutaneous melanoma: A randomised trial. The Lancet 200I, 358:866-9.

60. Cameron DA, Cornbleet MC, Mackie RM, Hunter JA, Gore M, Hancock B, Smyth JF, Scottish Melanoma Group: Adjuvant interferon alpha $2 \mathrm{~b}$ in high risk melanoma: The Scottish study. $\mathrm{Br} J \mathrm{Can}-$ cer 200I, 84: I I46-9.

61. Hancock BW, Wheatley K, Harris S, Ives N, Harrison G, Horsman JM, Middleton MR, Thatcher N, Lorigan PC, Marsden JR, Burrows L, Gore M: Adjuvant Interferon in High-Risk Melanoma: The AIM HIGH Study - United Kingdom Coordinating Committee on Cancer Research Randomized Study of Adjuvant Low-Dose Extended-Duration Interferon Alfa-2a in High-Risk Resected Malignant Melanoma. J Clin Oncol 2004, 22:53-6I.

62. Kleeberg UR, Suciu S, Brocker EB, Ruiter DJ, Chartier C, Lienard D, Marsden J, Schadendorf D, Eggermont AM, EORTC Melanoma Group in cooperation with the German Cancer Society (DKG): Final results of the EORTC I887I/DKG 80-I randomised phase III trial. rIFN-alpha2b versus rIFN-gamma versus ISCADOR $M$ versus observation after surgery in melanoma patients with either high-risk primary (thickness $>3 \mathbf{m m}$ ) or regional lymph node metastasis. Eur J Cancer 2004, 40:390-402.

63. Early Breast Cancer Trialists' Collaborative Group (EBCTCG): Effects of chemotherapy and hormonal therapy for early breast cancer on recurrence and 15-year survival: an overview of the randomised trials. The Lancet 2005, 365:1687-717.

64. de Gramont A, Boni C, Navarro M, Tabernero J, Hickish T, Topham C, Bonetti A, Clingan P, Lorenzato C, André T: Oxaliplatin/5FU/LV in adjuvant colon cancer: Updated efficacy results of the MOSAIC trial, including survival, with a median follow-up of six years [abstract]. Proc Am Soc Clin Oncol 2007, 25: $165 \mathrm{~S}$.

65. Arriagada R, Bergman B, Dunant A, Le Chevalier T, Pignon JP, Vansteenkiste J, International Adjuvant Lung Cancer Trial Collaborative Group: Cisplatin-based adjuvant chemotherapy in patients with completely resected non-small-cell lung cancer. $N$ EnglJ Med 2004, 350:351-60.

66. Trimbos JB, Vergote I, Bolis G, Vermorken JB, Mangioni C, Madronal C, Franchi M, Tateo S, Zanetta G, Scarfone G, Giurgea L, Timmers P, Coens C, Pecorelli S, EORTC-ACTION collaborators: European Organisation for Research and Treatment of Cancer-Adjuvant ChemoTherapy in Ovarian Neoplasm. Impact of adjuvant chemotherapy and surgical staging in early-stage ovarian carcinoma: European Organisation for Research and Treatment of Cancer-Adjuvant ChemoTherapy in Ovarian Neoplasm trial. J Natl Cancer Inst 2003, 95: I I3-25.

67. Trimbos JB, Parmar M, Vergote I, Guthrie D, Bolis G, Colombo N, Vermorken JB, Torri V, Mangioni C, Pecorelli S, Lissoni A, Swart AM, International Collaborative Ovarian Neoplasm I: European Organisation for Research and Treatment of Cancer Collaborators-Adjuvant ChemoTherapy un Ovarian Neoplasm.
International Collaborative Ovarian Neoplasm trial I and Adjuvant ChemoTherapy In Ovarian Neoplasm trial: two parallel randomized phase III trials of adjuvant chemotherapy in patients with early-stage ovarian carcinoma. J Natl Cancer Inst 2003, 95: 105-12.
Publish with Bio Med Central and every scientist can read your work free of charge

"BioMed Central will be the most significant development for disseminating the results of biomedical research in our lifetime. "

Sir Paul Nurse, Cancer Research UK

Your research papers will be:

- available free of charge to the entire biomedical community

- peer reviewed and published immediately upon acceptance

- cited in PubMed and archived on PubMed Central

- yours - you keep the copyright

Submit your manuscript here:

http://www.biomedcentral.com/info/publishing_adv.asp 